\title{
Urgent hyperbaric oxygen therapy for suicidal carbon monoxide poisoning: from a preliminary survey to a proposal for an integrated somatic-psychiatric protocol
}

\author{
Alessandra Costanza ${ }^{1,2^{*}}$ DD, Julia Ambrosetti ${ }^{3+}$, Philippe Spagnoli ${ }^{4}$, Andrea Amerio ${ }^{5,6,7}$, Andrea Aguglia ${ }^{5,6}$,
} Gianluca Serafini ${ }^{5,6}$, Mario Amore ${ }^{5,6}$, Guido Bondolfi ${ }^{1,8}$, François Sarasin ${ }^{1,9}$ and Rodrigue Pignel ${ }^{4}$

\begin{abstract}
A considerable number of patients who made a carbon monoxide (CO) suicidal attempt are treated with urgent hyperbaric oxygen therapy (HBOT). For these patients at potential persistent risk of suicide, the hyperbaric chamber is a dangerous environment and their management a complex challenge for the Emergency Department (ED) and Hyperbaric Medicine Unit (UMH) teams. We aimed to (1) identify cases of intentional CO poisoning treated with urgent HBOT in the UMH of the University Hospitals of Geneva (HUG) during 2011-2018 and (2) test a proposed operational and integrated somatic-psychiatric protocol based on acquired experience. A total of 311 patients with CO poisoning were treated using urgent HBOT, for which poisoning was assumed suicidal in 40 patients (12.9\%). This percentage appears greater than in other European countries. Both the excess of cases of intentional CO poisonings and difficulties encountered in their management resulted in the implementation of an operational and integrated somatic-psychiatric protocol addressing the entire patient's clinical trajectory, from the admission at EDHUG to the treatment at the UMH-HUG. The established institutional protocol includes (1) clinical evaluation, (2) suicide risk assessment, and (3) safety measures. This is the first report-at our best knowledge_of a protocol detailing a practical procedure algorithm and focusing on multidisciplinary and mutual collaboration between the medical-nursing teams at the ED, psychiatric ED, and UMH. Improvements in patient's safety and care team's sense of security were observed. In conclusion, the opportunity to refer to a standardized protocol was beneficial in that it offers both reduced risks for suicidal patients and reduced stress for care teams operating in very acute and complex situations. Further studies are needed.
\end{abstract}

Keywords: Hyperbaric medicine, Emergency medicine, Emergency psychiatry, Risk management, Suicide, Suicidal behavior, Suicide attempt, Intentional carbon monoxide intoxication

\footnotetext{
* Correspondence: alessandra.costanza@unige.ch

${ }^{+}$Alessandra Costanza and Julia Ambrosetti contributed equally to this work.

'Department of Psychiatry, Faculty of Medicine, University of Geneva (UNIGE), Geneva, Switzerland

${ }^{2}$ Department of Psychiatry, ASO Santi Antonio e Biagio e Cesare Arrigo Hospital, Alessandria, Italy

Full list of author information is available at the end of the article
}

(c) The Author(s). 2020 Open Access This article is licensed under a Creative Commons Attribution 4.0 International License, which permits use, sharing, adaptation, distribution and reproduction in any medium or format, as long as you give appropriate credit to the original author(s) and the source, provide a link to the Creative Commons licence, and indicate if changes were made. The images or other third party material in this article are included in the article's Creative Commons licence, unless indicated otherwise in a credit line to the material. If material is not included in the article's Creative Commons licence and your intended use is not permitted by statutory regulation or exceeds the permitted use, you will need to obtain permission directly from the copyright holder. To view a copy of this licence, visit http://creativecommons.org/licenses/by/4.0/ The Creative Commons Public Domain Dedication waiver (http://creativecommons.org/publicdomain/zero/1.0/) applies to the data made available in this article, unless otherwise stated in a credit line to the data. 


\section{Background}

Carbon monoxide ( $\mathrm{CO}$ ) is one of the leading causes of morbidity and mortality of toxic origin [1]. About 40$70 \%$ of American $\mathrm{CO}$ poisonings are intentional, whereas the majority of European cases are accidental [2]. Although suicide is the fourth leading cause of early death in Switzerland, CO-specific epidemiologic data is sparse $[3,4,5]$.

Severe CO poisoning can result in delayed encephalopathy, causing long-term neuropsychiatric symptoms, such as cognitive decline, personality changes, and affective disorders [6]. Although urgent hyperbaric oxygen therapy (HBOT) is not generally considered superior to normobaric oxygen therapy to prevent these sequelae [7], a number of $\mathrm{CO}$ poisonings, including intentional poisonings, are treated with HBOT.

$\mathrm{CO}$ poisoning represents a challenge for the staff of the Department of Emergency (ED). Among suicidal patients, this diagnosis is complicated by frequent simultaneous consumption of alcohol and drugs. Although the risk of repeating a suicide attempted in a hyperbaric chamber is low (especially for monoplace chambers versus multiplace chambers), the hyperbaric chamber is a hazardous environment for these patients, potentially still presenting an acute suicide risk, because of the presence of cables, devices, and other medical equipment (Fig. 1). Finally, in contrast to the standard decompression protocol (requiring at least $15 \mathrm{~min}$ ), the necessity of applying a faster decompression procedure (requiring 3 min) in cases of acute psychomotor agitation-not rare in these patients-increases the risk of decompression sickness $[2,7,8]$.

The aims of this text were to (1) determine if there are sufficient numbers of patients to support adoption of an operational and integrated somatic-psychiatric protocol for patients who made a suicide attempt (SA) by $\mathrm{CO}$ poisoning, based on acquired experience, and (2) outline details of this proposed protocol and begin to test its efficacy by implementation in the clinic.

\section{Methods}

\section{Case identification}

Annual numbers of patients with $\mathrm{CO}$ poisoning admitted at the ED-HUG and requiring urgent HBOT in the UMH-HUG from January 2011 to December 2018 were retrospectively collected. The percentage of intentional poisoning was calculated to determine whether there were a sufficient number of patients with adverse events to justify adoption of a protocol. Confidential/sensitive personal health information was not collected. As attested in the statement of 17 July 2020, this project did not need to be reviewed by the Geneva Cantonal of the Research Ethics Commission (CCER), because its aims are outside of the scope of the law. This Act applies to research concerning human diseases and concerning the structure and the function of the human body as defined in the Art. 2 of the Human Research Act (HRA) [9].

\section{Proposed protocol}

Both the excess of cases of intentional $\mathrm{CO}$ poisonings and difficulties encountered in their management resulted in the implementation of an operational and integrated somatic-psychiatric protocol addressing the entire patient's clinical trajectory, from the admission at ED to the treatment at the UMH. This project was facilitated by the geographical proximity in the HUG of the ED, the psychiatric ED, and the UMH. The established protocol includes (1) clinical evaluation, (2) suicide risk assessment, and (3) safety measures (Fig. 2).

Suicide risk was assessed by the Risk, Urgency, and Dangerousness (RUD) scale [10]. Evaluation of these parameters results in four RUD profiles for suicidal behavior (high, medium, weak, absent) with consequential clinical attitudes.

Psychopharmacological indications to be adopted in cases of major anxiety or psychomotor agitation (Fig. 2) follow the dedicated HUG protocol [11]. The latter is based on the consensus statement of the American Association for Emergency Psychiatry [12]. First-line therapy is orally administered $2 \mathrm{mg}$ lorazepam combined with $5-10 \mathrm{mg}$ sublingual olanzapine $(2-5 \mathrm{mg}$ haloperidol

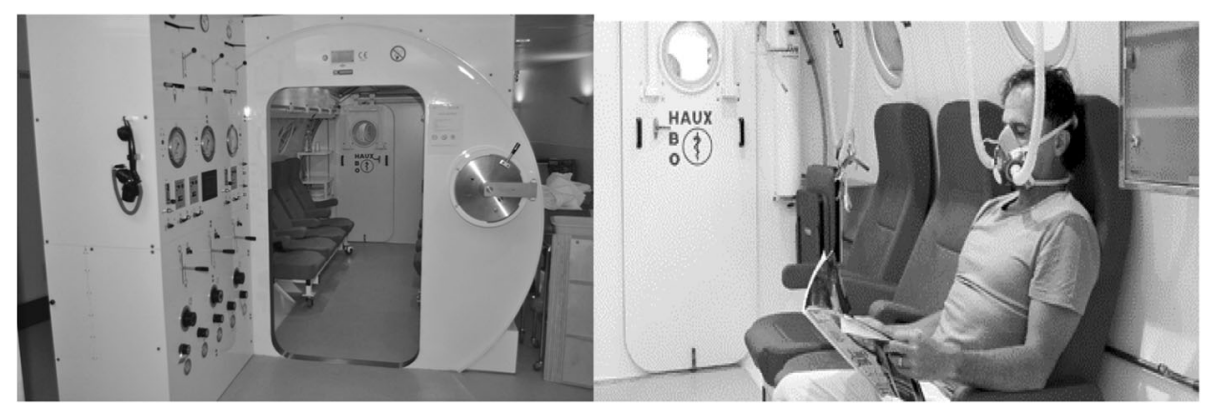

Fig. 1 The interior of a multiplace hyperbaric chamber 


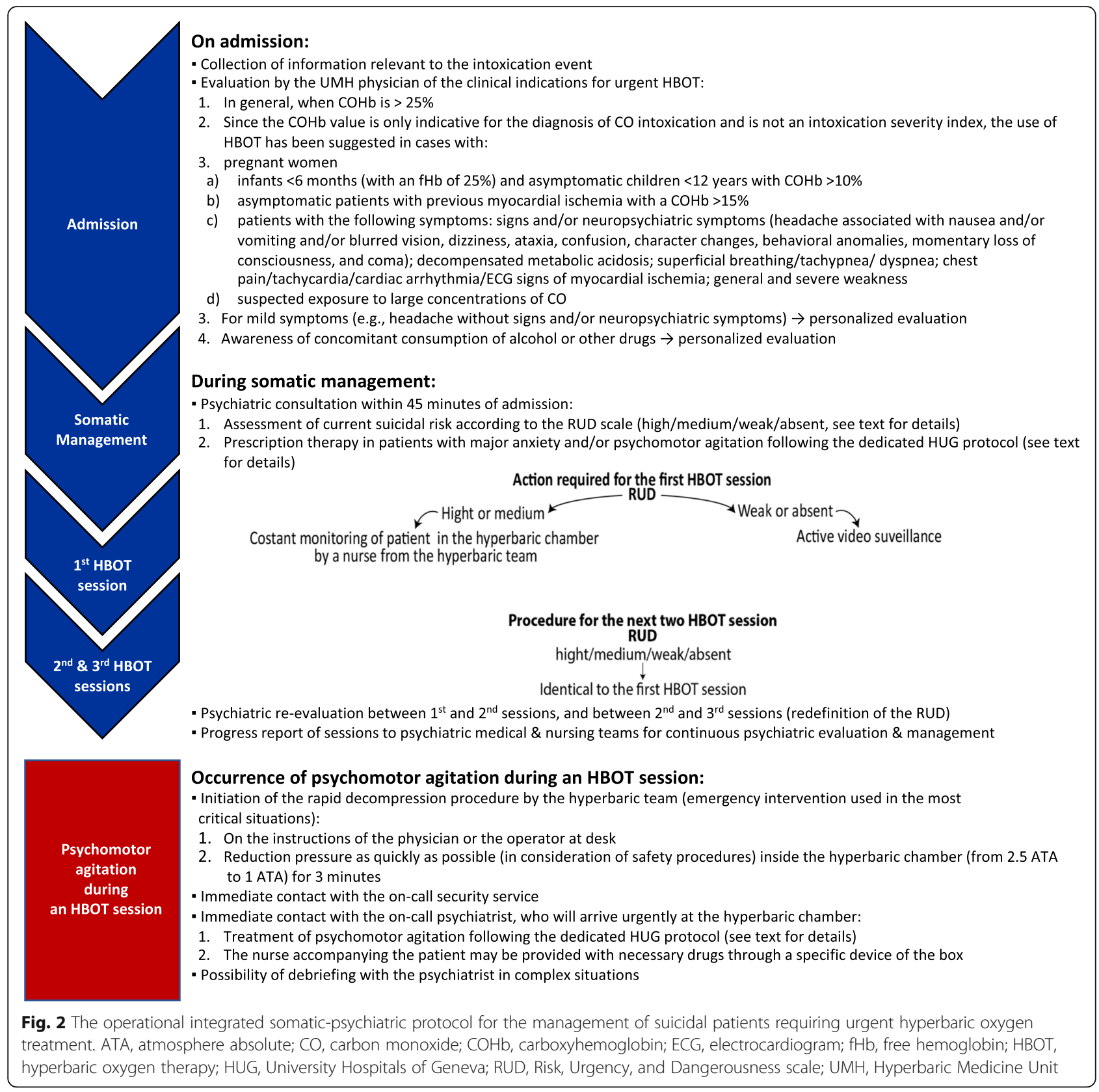

if olanzapine is unavailable). As a last resort, intramuscular $2 \mathrm{mg}$ lorazepam and $5 \mathrm{mg}$ haloperidol are used ( $2.5 \mathrm{mg}$ midazolam if lorazepam is unavailable). These regimens can be repeated following a 20-30-min interval in patients with persistent agitation and only following somatic reassessment. Regular supervision is required every $30 \mathrm{~min}$ after sedation including monitoring of vital signs (Glasgow Coma Scale, arterial pressure, heart rate, oxygen saturation, blood glucose). Lack of a response should lead to consideration of sedation under airway protection by an anesthetist. These indications should be adapted to the patients' clinical characteristics, including reducing treatment dosage in the elderly, and the sole or priority use of benzodiazepines in case of documented/ suspected pregnancy, alcohol and substance abuse, alcohol and substance withdrawal, concomitant methadone therapy, and prolonged QTc history.

\section{Results and discussion}

A total of 311 patients were treated for $\mathrm{CO}$ poisoning over the period 2011-2018. They received hyperbaric oxygen alternating with a 5-min break (to reduce risk of oxygen neurotoxicity) at 2.5 ATA over the course of 3 sessions $(2.5,1.5$, and $1.5 \mathrm{~h})$ within the first $24 \mathrm{~h}$. Intentional poisoning was observed in $12.9 \%(n=40)$ of cases, with most occurrences in $2012(23.3 \%, n=7)$ and 
the least in $2017(7.4 \%, n=4)$ (Table 1). The percentage of intentional $\mathrm{CO}$ poisoning treated using urgent HBOT appears greater in our sample compared to other European countries. For example, intentional $\mathrm{CO}$ poisonings in the $\mathrm{UMH}$ of Marseille were estimated at 1\% of all treated CO poisonings (Dr. M. Coulange, Centre Hyperbare St. Marguerite, unpublished data). Comparative studies between the UMH various sites inside and outside of Switzerland are needed.

Before the implementation of this protocol (years 2011-2013), 14 patients were treated for intentional CO intoxication, which included 4 cases of severe psychomotor agitation requiring a psychiatrist's intervention. Subsequently, after the implementation of the protocol (years 2014-2018), 26 patients were treated for intentional $\mathrm{CO}$ intoxication, which included 2 cases of mild-moderate psychomotor agitation requiring a psychiatrist's intervention. The risk of committing suicide in a hyperbaric chamber is very low, and this is especially true for monoplace chambers. Nonetheless, we documented 3 cases of a renewed suicide attempt within the multiplace hyperbaric chamber between 2011 and 2013, and no cases afterwards. Although these numbers are not high enough for a rigorous statistical analysis, the trends do suggest that patients may be benefiting from this protocol in terms of reduced severity of psychomotor agitation and lower number of renewed SA.

Improvements in patient's safety and the UMH team's sense of security were observed through semi-structured interviews with staff. Before the protocol's introduction, four cases of severe psychomotor agitation were treated with the intervention of a psychiatrist and there were three cases of a renewed suicide attempt within the hyperbaric chamber. However, at this time, the psychiatrist was not made aware of the risks associated with the hyperbaric chamber nor HBOT procedures. We believe that a more rapid intervention and implementation

Table 1 Accidental and intentional carbon monoxide (CO) poisonings treated using hyperbaric oxygen therapy (HBOT) at the Hyperbaric Medicine Unit of the University Hospitals of Geneva (HUG)

\begin{tabular}{llll}
\hline Year & Total CO poisonings & \multicolumn{2}{l}{ Intentional CO poisonings } \\
\cline { 3 - 4 } & Patients $(\boldsymbol{n}=\mathbf{3 1 1})$ & Patients $(\boldsymbol{n}=\mathbf{4 0})$ & Percentage $\mathbf{( 1 2 . 9 \% )}$ \\
\hline 2011 & $n=22$ & $n=5$ & $22.7 \%$ \\
2012 & $n=30$ & $n=7$ & $23.3 \%$ \\
2013 & $n=16$ & $n=2$ & $12.5 \%$ \\
2014 & $n=48$ & $n=5$ & $10.5 \%$ \\
2015 & $n=40$ & $n=4$ & $10.0 \%$ \\
2016 & $n=44$ & $n=4$ & $9.1 \%$ \\
2017 & $n=54$ & $n=4$ & $7.4 \%$ \\
2018 & $n=57$ & $n=9$ & $15.8 \%$ \\
\hline
\end{tabular}

of the protocol, including administering psychopharmacologic drugs into the chamber, could have negated worsening of the psychomotor agitation. No further incidents occurred after the protocol's implementation. Concerning subjective impressions of the UMH team, globally, the opportunity to refer to a clear multidisciplinary standardized protocol during acute and complex situations was reported. Some examples of responses of operators during semistructured interviews were as follows: they could dispose of clear indication during emergencies; when they called for the psychiatrist, the latter was aware of this protocol and he could immediately operate; they prepared with the aid of the psychiatrist a stock of potential necessary psychopharmacological drugs, so the latter were immediately ready when necessary; even if an accident occurred, they know that they follow institutional procedures; finally, they know that they can benefit from debriefing seances with the psychiatrist for complex situations.

These observations suggest that an institutional somatic-psychiatric protocol can be beneficial as it offers both a decreased risk for these suicidal patients and reduced stress for the care teams. Practice recommendations in the diagnosis, management, and prevention of $\mathrm{CO}$ poisoning are available $[7,13]$, but-at our best knowledge-this is the first report of a multidisciplinary protocol detailing clinical procedures, suicide risk assessment, and safety measures focusing on mutual collaboration between the medical-nursing teams at the ED, psychiatric ED, and UMH.

\section{Limitations}

Our work has several limitations. First, the lack of sociodemographic and diagnostic information in this preliminary survey did not allow for identification of confounding factors. Second, formal comparisons between the $\mathrm{UMH}$ various sites inside and outside of Switzerland were not made. Third, the only empirical observations on the outcomes of the proposed protocol in the absence of statistical data support did not permit objective measures of improvements in utility and safeness [14].

\section{Conclusions}

In conclusion, we have formulated a multidisciplinary coordinated approach to address SA made by $\mathrm{CO}$ poisoning. The descriptive data collected thus far suggests that a somatic-psychiatric protocol can be helpful as it offers both a decreased risk for the suicidal patient and reduced stress for the care teams. It will serve as a framework for future quantitative studies.

\footnotetext{
Abbreviations

CO: Carbon monoxide; ED: Emergency Department; HBOT: Hyperbaric oxygen therapy; HUG: University Hospitals of Geneva; QTc: Corrected QT interval; RUD: Risk, Urgency, and Dangerousness; UMH: Hyperbaric Medicine Unit
} 


\section{Acknowledgements}

We are deeply grateful to Dr. Mirko Lombardo for his precious technical support and Dr. Sara De Vita for her graphical contribution.

\section{Authors' contributions}

A.C. and J.A. drafted the primary manuscript, contributed to the conceptualization of the study, and participated to the study selection/data collection; P.S. made the primary study selection/data collection and contributed to the conceptualization of the study; A.Am. and A.Ag. revised both the primary manuscript and the study selection/data collection; G.S. M.A., G.B., F.S., and R.P. revised the manuscript and supervised all the work. All authors have read and agreed to the published version of the manuscript.

\section{Funding}

This work did not receive any specific grant from funding agencies in the public, commercial, or not-for-profit sectors.

\section{Availability of data and materials}

The datasets generated for this study are available on request to the corresponding author.

\section{Ethics approval and consent to participate}

This survey did not involve the collection or use of confidential or sensitive personal health information, but exclusively concerned the annual number of patients with $\mathrm{CO}$ poisoning and the percentage of patients with intentional poisoning. Ethics approval was not required under the Geneva jurisdiction for reporting the data presented in this study. The present study was conducted in compliance with the Helsinki Declaration of 1975, as revised in October 2013.

\section{Consent for publication}

Not applicable

\section{Competing interests}

All authors declare that they have no competing interests.

\section{Author details}

'Department of Psychiatry, Faculty of Medicine, University of Geneva (UNIGE), Geneva, Switzerland. ²Department of Psychiatry, ASO Santi Antonio e Biagio e Cesare Arrigo Hospital, Alessandria, Italy. ${ }^{3}$ Emergency Department and Psychiatry Department, Emergency Psychiatric Unit (UAUP), Geneva University Hospitals (HUG), Geneva, Switzerland. ${ }^{4}$ Emergency Department, Hyperbaric Medicine Unit, Geneva University Hospitals (HUG), Geneva, Switzerland. ${ }^{5}$ Department of Neuroscience, Rehabilitation, Ophthalmology, Genetics, Maternal and Child Health (DINOGMI), Section of Psychiatry, University of Genoa, Genoa, Italy. ${ }^{6}$ RCCS Ospedale Policlinico San Martino, Genoa, Italy. ${ }^{7}$ Department of Psychiatry, Tufts University, Boston, USA. ${ }^{8}$ Department of Psychiatry, Service of Liaison Psychiatry and Crisis Intervention (SPLIC), Geneva University Hospitals (HUG), Geneva, Switzerland. ${ }^{9}$ Emergency Department, Emergency Medicine Unit, Geneva University Hospitals (HUG), Geneva, Switzerland.

Received: 4 July 2020 Accepted: 21 November 2020

Published online: 02 December 2020

\section{References}

1. Prockop LD, Chichkova RI. Carbon monoxide intoxication: an updated review. J Neurol Sci. 2007;262:122-30.

2. Schaub E, Pellegrini M, Pugin D. Carbon monoxide poisoning: an update for 2009. Rev Med Suisse. 2009:5:1606-9.

3. Ostertag L, Golay P, Dorogi Y, Brovelli S, Bertran M, Cromec I, et al. The implementation and first insights of the French-speaking Swiss programme for monitoring self-harm. Swiss Med Wkly. 2019;149:w20016.

4. Costanza A, Mazzola V, Radomska M, Amerio A, Aguglia A, Prada P, et al. Who consult an adult psychiatric emergency department? Pertinence of admissions and opportunities for telepsychiatry. Medicina. 2020a;56:295.

5. Costanza A, Amerio A, Radomska M, Ambrosetti J, Di Marco S, Prelati M, Aguglia A, Serafini G, Amore M, Bondolfi G, Michaud L, Pompili M. Suicidality assessement of the elderly with physical illness in the Emergency Department. Front Psychiatry. 2020b;11:558974.
6. Borras L, Constant E, De Timary P, Huguelet P, Khazaal Y. Long-term psychiatric consequences of carbon monoxide poisoning: a case report and literature review. Rev Med Interne. 2009;30:43-8.

7. American College of Emergency Physicians Clinical Policies Subcommittee (Writing Committee on Carbon Monoxide Poisoning: Wolf SJ, Maloney GE, Shih RD, Shy BD, Brown MD). Clinical policy: critical issues in the evaluation and management of adult patients presenting to the emergency department with acute carbon monoxide poisoning. Ann Emerg Med 2017; 69: 98-107.

8. Ng PCY, Long B, Koyfman A. Clinical chameleons: an emergency medicine focused review of carbon monoxide poisoning. Intern Emerg Med. 2018;13: 223-9.

9. World Medical Association. World Medical Association Declaration of Helsinki: ethical principles for medical research involving human subjects. JAMA. 2013;310:2191-4.

10. Séguin $M$, Terra JL. [Suicidal crisis intervention training: trainer's manual]. Document de la Direction Générale de la Sante, Ministère de la Santé et de la Protection Sociale, Université du Quebec et Outaoais (UQO). 2004.

11. de Néris M, Costanza A, Besson M, Greiner C, Prada P, Ambrosetti J. Suicidal crisis and suicide prevention: psychopharmacological aspects. Rev Med Suisse. 2020;16:314-7.

12. Wilson MP, Pepper D, Currier GW, Holloman GH Jr, Feifel D. The psychopharmacology of agitation: consensus statement of the American Association for Emergency Psychiatry project BETA psychopharmacology workgroup. West J Emerg Med. 2012;13:26-34.

13. Hampson NB, Piantadosi CA, Thom SR, Weaver LK. Practice recommendations in the diagnosis, management, and prevention of carbon monoxide poisoning. Am J Respir Crit Care Med 2012;186:1095-101.

14. Amerio A, Starace F, Costanza A, Serafini G, Aguglia A, Odone A, et al. Putting Codman's lesson to work: measuring and improving the quality of Italian mental health care. Acta Psychiatr Scand. 2020;141:91-2.

\section{Publisher's Note}

Springer Nature remains neutral with regard to jurisdictional claims in published maps and institutional affiliations.

\section{Ready to submit your research? Choose BMC and benefit from:}

- fast, convenient online submission

- thorough peer review by experienced researchers in your field

- rapid publication on acceptance

- support for research data, including large and complex data types

- gold Open Access which fosters wider collaboration and increased citations

- maximum visibility for your research: over $100 \mathrm{M}$ website views per year

At BMC, research is always in progress.

Learn more biomedcentral.com/submissions 